- RAM, REV. ADM. MACKENZIE, 15(5) • SÃO PAULO, SP • SET./OUT. 2014 • ISSN 1518-6776 (impresso) • ISSN 1678-6971 (on-line) • http://dx.doi.org/10.1590/1678-69712014/administracao.v15n5p195-223. Submissão: 24 fev. 2014. Aceitação: 19 ago. 2014. Sistema de avaliação: às cegas dupla (double blind review).

UNIVERSIDADE PRESBITERIANA MACKENZIE. Silvio Popadiuk (Ed.), Aureliano Angel Bressan (Ed. Seção), p. 195-223.

\title{
- \\ BANCOS VERSUS COOPERATIVAS DE CRÉDITO: UM ESTUDO DOS ÍNDICES DE EFICIÊNCIA E RECEITA DA PRESTAÇÃO DE SERVIÇOS ENT'RE 2002 E 2012
}

ALBERTO BORGES MATIAS

Livre-docente em Administração Financeira pela Faculdade de Economia, Administração e Contabilidade da Universidade de São Paulo (FEA-USP).

Professor Titular do Departamento de Administração da Universidade de São Paulo (USP). Avenida dos Bandeirantes, 3.900, bloco A, Monte Alegre, Ribeirão Preto - SP - Brasil - CEP 14040-900 E-mail:matias@usp.br

\section{GISLAINE DE MIRANDA QUAGLIO}

Mestre em Economia pela Faculdade de Ciências e Letras da Universidade Estadual "Julio de Mesquita Filho" (Unesp). Supervisora de Pesquisa do Centro de Pesquisas do Instituto de Ensino e Pesquisa em Administração (Inepad). Rua Marechal Rondon, 571, Sumaré, Ribeirão Preto - SP - Brasil - CEP 14020-220

E-mail: gislaine.dmq@gmail.com

\section{JOÃO PAULO RESENDE DE LIMA}

Graduando em Ciências Contábeis pela Faculdade de Economia, Administração e Contabilidade da Universidade de São Paulo (FEA-USP). Pesquisador do Centro de Pesquisas do Instituto de Ensino e Pesquisa em Administração (Inepad).

Rua Marechal Rondon, 571, Sumaré, Ribeirão Preto - SP - Brasil - CEP 14020-220 E-mail: jp.resendelima@hotmail.com

\section{VINÍCIUS MEDEIROS MAGNANI}

Graduando em Economia Empresarial e Controladoria pela Faculdade de Economia, Administração e Contabilidade da Universidade de São Paulo (FEA-USP).

Pesquisador do Centro de Pesquisas do Instituto de Ensino e Pesquisa em Administração (Inepad). Rua Marechal Rondon, 571, Sumaré, Ribeirão Preto - SP - Brasil - CEP 14020-220

E-mail: vinicius_magnani@hotmail.com

Este artigo pode ser copiado, distribuído, exibido, transmitido ou adaptado desde que citados, de forma clara e explícita, o nome da revista, a edição, o ano e as páginas nas quais o artigo foi publicado originalmente, mas sem sugerir que a RAM endosse a reutilização do artigo. Esse termo de licenciamento deve ser explicitado para os casos de reutilização ou distribuição para terceiros. Não é permitido o uso para fins comerciais. 


\section{RESUMO}

O presente estudo apresenta caráter descritivo e visa analisar o índice de eficiência e a evolução das receitas de prestação de serviços das cooperativas de crédito em comparação às instituições bancárias privadas e públicas. Segundo dados do Banco Central do Brasil, a relação PIB/crédito situou-se em 55,5\% no ano de 2012 , entretanto, ainda não se compara a países desenvolvidos, que atinge patamares acima de $100 \%$. A amostra consiste nas maiores instituições bancárias e cooperativistas selecionadas de acordo com o critério "ativo total", totalizando uma média de 69,31\% para as instituições bancárias e 61,33\% para as cooperativas de crédito. Para análise das variáveis foram empregados índices de eficiência, análise vertical e horizontal das receitas de prestação de serviço no período entre 2002 e 2012 . O índice de eficiência é um importante indicador, pois relaciona os insumos aplicados na produção e os produtos obtidos nesse processo. A análise das rendas com prestação de serviços é significativa, pois tem se mostrado cada vez mais relevante no desempenho financeiro das instituições financeiras. Os resultados obtidos demonstraram que os índices de eficiência dos bancos privados apresentaram os maiores níveis entre os segmentos analisados, seguidos pelos bancos públicos e, por fim, pelas cooperativas de crédito. A predominância dos bancos privados não foi abalada nos anos de crise, ao contrário dos bancos públicos, que foram ultrapassados pelo segmento cooperativista de crédito nos anos de 2008-2009 e 20I2. Diante das contas que formam o índice, constatou-se que, até 2006, o comprometimento do RBIF com as despesas estruturais nas cooperativas foi semelhante ao verificado nos bancos públicos, porém maior do que o dos bancos privados. Tal comportamento se diferenciou entre os anos de 2007-2010 e 2012, quando esse indicador apresentou queda significativa no segmento cooperativista. Por fim, nas evoluções horizontal e vertical verificou-se que, apesar do crescimento significativo registrado pelas cooperativas de crédito e da convergência no grau de participação entre os segmentos, a participação das receitas de prestação de 
serviço ainda é maior no segmento bancário do que no cooperativista de crédito. Esse fato pode representar um elemento de potencialidade a ser explorado pelas cooperativas na busca pela eficiência.

\section{PALAVRAS-CHAVE}

Eficiência. Bancos. Cooperativas de crédito. Receitas de prestação de serviços. Mercado de crédito.

\section{INTRODUÇÃO}

O Sistema Financeiro Nacional (SFN) é composto, dentre outros, por dois importantes mercados, o mercado de crédito e o mercado de capitais. O mercado de capitais se restringe a algumas grandes empresas que conseguem realizar captações de recursos por meio da emissão de debêntures, por exemplo. Por sua vez, o mercado de crédito é uma das mais importantes fontes de financiamento para empresas de vários setores.

Segundo dados do Banco Central do Brasil - BACEN (2013), o saldo total das operações de crédito no Brasil chegou, ao final de 20I2, a $\mathrm{R} \$ 2.367$ bilhões e a relação do crédito/Produto Interno Bruto (PIB) situou-se em 55,5\%. Ao comparar a mesma relação nos países desenvolvidos, com média de $227 \%$, observa-se que o mercado de crédito nacional tem potencial para crescer.

Dada a importância do mercado de crédito para o financiamento das empresas e, consequentemente, da economia como um todo, este trabalho se mostra relevante ao apresentar a comparação do segmento de cooperativas de crédito, cujo crescimento nas operações de crédito, segundo dados do BACEN (2013), passou de R \$ I bilhão em I996 para R \$ 45,5 bilhões em 20I2, considerando os segmentos bancários público e privado. Dessa forma, tal comparação se mostra pertinente tendo em vista que nos últimos anos as cooperativas de crédito no Brasil começaram a ganhar mercado e se configuraram como alternativas viáveis de aplicação e captação no mercado de crédito nacional.

Este trabalho propõe a análise e comparação do índice de eficiência dos dois segmentos indicados no período entre 2002 e 20I2. Além do índice de eficiência, também são analisadas as evoluções vertical e horizontal da renda de prestação de serviços, considerada na literatura um componente significativo no desempenho das instituições financeiras em geral. 
O presente estudo é desenvolvido em cinco seções, tendo início nesta introdução. Na segunda seção é apresentada a discussão teórica sobre origem e conceituação do cooperativismo, da origem e papel desempenhado pelas cooperativas de crédito no Brasil e no mundo e, por fim, é discutido o crédito bancário. Na terceira seção é apresentada a metodologia empregada no trabalho, na quarta seção são apresentados os resultados obtidos e na quinta seção, as considerações finais.

\section{REFERENCIAL TEÓRICO}

Neste tópico serão apresentadas as discussões teóricas sobre cooperativismo no Brasil e no mundo, crédito bancário e a conceituação de eficiência.

\subsection{COOPERATIVISMO: ORIGEM E DEFINIÇÃO}

Como alternativa ao desemprego e à crise econômica decorrentes da Revolução Industrial, 28 tecelões de Rochdale, Manchester, fundaram a primeira cooperativa de que se tem registro. A cooperativa fundada por esses tecelões foi constituída em I844, tinha características de uma cooperativa de consumo e recebeu o nome de Sociedade dos Probos Pioneiros de Rochdale (Geriz, 2004; Stefanello, Freitas, \& Staduto, 2004).

A Sociedade dos Probos Pioneiros de Rochdale criou os princípios cooperativistas que são tidos como base do cooperativismo autêntico até os dias de hoje. Os princípios cooperativistas são: adesão voluntária e livre; gestão democrática; participação econômica dos membros; autonomia e independência; educação, formação e informação; intercooperação; interesse pela comunidade (Geriz, 2004; Stefanello, Freitas, \& Staduto, 2004).

A Aliança Cooperativista Internacional - ICA (20I3) conceitua cooperativa como "uma associação de pessoas unidas voluntariamente para satisfazer suas necessidades econômicas, sociais e culturais comuns através de uma empresa de propriedade comum e democraticamente controlada". A Organização das Cooperativas Brasileiras - OCB (2013) define cooperativa como a organização de pessoas baseada em valores de ajuda mútua, responsabilidade, democracia, igualdade, equidade e solidariedade. $\mathrm{O}$ artigo $4^{\circ}$ da Lei n. 5.764/7I conceitua cooperativa como “[...] sociedades de pessoas, com forma e natureza jurídica próprias, de natureza civil, não sujeitas a falência, constituídas para prestar serviços aos associados, distinguindo-se das demais sociedades" pelas seguintes características listadas no Quadro I. 


\section{QUADRO I}

\section{CARACTERÍSTICAS DAS COOPERATIVAS}

\section{I - adesão voluntária, com número ilimitado de associados, salvo impossibilidade técnica de prestação de serviços;}

VII - retorno das sobras líquidas do exercício, proporcionalmente às operações realizadas pelo associado, salvo deliberação em contrário da Assembleia Geral;

VIII - indivisibilidade dos fundos de Reserva e de Assistência Técnica Educacional e Social;

II - variabilidade do capital social representado por quotas-partes;

IX - neutralidade política e indiscriminação religiosa, racial e social; de proporcionalidade, se assim for mais adequado para o cumprimento dos objetivos sociais;

IV - inacessibilidade das quotas-partes do capital a terceiros, estranhos à sociedade;
X - prestação de assistência aos associados,

e, quando previsto nos estatutos, aos empregados da cooperativa;

$\mathrm{V}$ - singularidade de voto, podendo as cooperativas centrais, federações e $X I$ - área de admissão de associados limitada confederações de cooperativas, com exceção às possibilidades de reunião, controle, das que exerçam atividade de crédito, optar operações e prestação de serviços. pelo critério da proporcionalidade;

$\mathrm{VI}$ - quórum para o funcionamento e deliberação da Assembleia Geral baseado no número de associados e não no capital;

Fonte: Lei n. 5.764, I97I.

Segundo Santos (2009), um dos maiores problemas dos empresários de pequenas empresas é a obtenção de crédito com condições de taxas, prazos e garantias adequadas às suas necessidades. Partindo dessa necessidade e do conceito de cooperativismo, surgiram as primeiras cooperativas de crédito.

De acordo com Geriz (2004), em I848 foi fundada a primeira cooperativa de crédito na Alemanha para satisfazer às necessidades de crédito rural. Santos (2009) complementa indicando que essa cooperativa surgiu da iniciativa de Friedrich Raiffeisen e, por esse motivo, as cooperativas de iniciativa rural começaram a ser identificadas pelo nome Raiffeisen. 
Pinheiro (2008, p. 7) define as cooperativas de crédito como "instituições financeiras constituídas sob a forma de sociedade cooperativa, tendo por objetivo a prestação de serviços financeiros aos associados [...]". Mélian e Cabo (2006) afirmam que as cooperativas de crédito são instituições financeiras que, juntamente com os bancos, formam o sistema bancário. Entretanto, segundo Mélian e Cabo (2006), as cooperativas diferem das outras instituições financeiras devido a sua forma jurídica, visto que estas são consideradas organizações do terceiro setor. De acordo com Assaf Neto (20I4, p. 5I), "as cooperativas de crédito são instituições voltadas a viabilizar créditos aos seus associados, além de prestar determinados serviços". Wheelock e Wilson (20I3) conceituam cooperativa de crédito como uma organização mútua que provê depósitos, empréstimos e outros serviços financeiros a membros vinculados à instituição.

Apesar de serem instituições financeiras e prestarem serviços semelhantes, as cooperativas de crédito apresentam diferenças em relação às instituições bancárias. As principais diferenças entre as duas instituições podem ser observadas no Quadro 2.

\section{QUADRO 2}

PRINCIPAIS DIFERENÇAS ENTRE UMA COOPERATIVA DE CRÉDITO E UMA INSTITUIÇÃO FINANCEIRA (BANCO)

\begin{tabular}{ll}
\hline COOPERATIVAS & BANCOS \\
\hline $\begin{array}{l}\text { Sociedade simples, de pessoas, sem fins } \\
\text { lucrativos. }\end{array}$ & $\begin{array}{l}\text { Sociedade empresária, de capital, prioriza } \\
\text { o lucro para os acionistas. }\end{array}$ \\
\hline Número ilimitado de associados. & Número limitado de ações. \\
\hline Cada associado (pessoa) tem um voto. & Voto proporcional às ações ordinárias. \\
\hline $\begin{array}{l}\text { As cotas são inacessíveis a estranhos à } \\
\text { cooperativa, ainda que por herança. }\end{array}$ & $\begin{array}{l}\text { As ações são livremente negociadas } \\
\text { e/ou transferidas. }\end{array}$ \\
\hline $\begin{array}{l}\text { Os resultados financeiros oriundos de atos } \\
\text { cooperativos são isentos de tributos. }\end{array}$ & $\begin{array}{l}\text { Os resultados positivos são altamente } \\
\text { tributados. }\end{array}$ \\
\hline $\begin{array}{l}\text { As sobras (resultado positivo entre os } \\
\text { ingressos e dispêndios) são devolvidas aos } \\
\text { associados, proporcionalmente às suas } \\
\text { operações com a cooperativa no exercício. }\end{array}$ & $\begin{array}{l}\text { O lucro líquido fica à disposição dos } \\
\text { ações ou participação no capital do banco. }\end{array}$ \\
\hline \begin{tabular}{l} 
Desenvolve-se pela colaboração. \\
\hline
\end{tabular} & \begin{tabular}{l} 
Avança pela competição. \\
\hline
\end{tabular}
\end{tabular}

Fonte: Santos (2009). 


\subsection{COOPERATIVISMO DE CRÉDITO NO MUNDO E NO BRASIL}

De acordo com dados do Conselho Mundial das Cooperativas de Crédito Woccu (20II, 20I2), 20I2 apresentou crescimento de 9,68\% em relação a 20II, totalizando 55.952 cooperativas de crédito espalhadas pelo mundo. Apesar de apresentar crescimento no número de cooperativas, a percentagem de população economicamente ativa associada a uma cooperativa de crédito caiu de $7,8 \%$ para $7,72 \%$, fato que pode ser explicado com um possível aumento da população ativa. Já o número de membros das cooperativas cresceu I,90\% de 20 II para 20I2, totalizando 200,2 milhões (Conselho Mundial das Cooperativas de Crédito, 20II, 20I2).

Com base na Tabela I, elaborada com dados das cooperativas de crédito associadas ao Woccu, é possível observar que atualmente o continente americano tem o maior número de associados e população economicamente ativa, apesar de não ser o continente com o maior número de cooperativas.

\section{TABELA I}

COOPERATIVAS DE CREDITO PELO MUNDO

\begin{tabular}{lcccccc}
\hline CONTINENTE & PAISES & $\begin{array}{c}\text { COOPERATIVAS } \\
\text { DE CRÉDITO }\end{array}$ & ASSOCIADOS & $\begin{array}{c}\text { POPULAÇÃO } \\
\text { ECONOMICAMENTE } \\
\text { ATIVA }\end{array}$ & ATIVOS (U\$) & $\begin{array}{c}\text { EMPRÉSTIMOS } \\
\text { (U\$) }\end{array}$ \\
\hline África & 23 & 20.831 & 16 milhões & $6,43 \%$ & 5,6 bilhões & 4,9 bilhões \\
\hline $\begin{array}{l}\text { América do } \\
\text { Norte }\end{array}$ & 2 & 7.731 & 105,3 milhões & $45,23 \%$ & 1.331 bilhões & 851 bilhões \\
\hline $\begin{array}{l}\text { América } \\
\text { Latina }\end{array}$ & 15 & 2.446 & 20,8 milhões & $6,39 \%$ & 57,3 bilhões & 31,9 bilhões \\
\hline $\begin{array}{l}\text { América } \\
\text { Central }\end{array}$ & 19 & 412 & 3 milhões & $17,50 \%$ & 5,6 bilhões & 3,6 bilhões \\
\hline Ásia & 21 & 21.934 & 41,3 milhões & $2,74 \%$ & 176,2 bilhões & 106,7 bilhões \\
\hline Europa & 12 & 2.320 & 8,6 milhões & $3,67 \%$ & 26,4 bilhões & 12 bilhões \\
\hline Oceania & 9 & 278 & 5,1 milhões & $21,62 \%$ & 91 bilhões & 73,5 bilhões \\
\hline TOTAL & 101 & 55.952 & 200,1 milhões & $7,72 \%$ & 1,693 trilhões & 1,084 trilhões \\
\hline
\end{tabular}

Fonte: World Council of Credit Unions (2012). 
O Brasil, no ano de 20I2, registrou 64I cooperativas associadas ao Woccu, praticamente a metade do total de cooperativas de crédito existentes no país, que, conforme Melo Sobrinho, Soares e Meinen (2013), somava no mesmo ano em questão o total de I.216 cooperativas.

Na América do Norte, o país com maior destaque são os Estados Unidos, com 6.960 cooperativas e 95 milhões de associados. Na América Latina, o país que se destaca é o Equador, com 896 cooperativas de crédito. Por fim, na América Central, o destaque fica com Trinidad e Tobago, que possuem i29 cooperativas de crédito e 514.680 associados.

No continente europeu destaca-se a Ucrânia, com GI7 cooperativas de crédito e I,I milhão de associados. A Índia é o país asiático com maior participação nas cooperativas, contando com I.6I8 instituições e 20 milhões de associados. Por fim, na Oceania, a Austrália tem a maior concentração de instituições por possuir I03 cooperativas de crédito com 4,5 milhões de associados.

Assim como em outros países, as cooperativas de crédito no Brasil se iniciaram entre a segunda metade do século XIX e início do século XX. Na literatura, é possível encontrar diferentes datas do surgimento destas. De acordo com Hafemann e Floriano (2010) e Santos (2009), as cooperativas de crédito no Brasil tiveram início em I902, sendo a primeira fundada pelo Padre Teodoro Amstad, que teria feito o primeiro depósito no valor de Ioo mil réis, na cidade de Nova Petrópolis, Rio Grande do Sul.

Entretanto, Pinheiro (2008) afirma que a primeira cooperativa foi a Sociedade Cooperativa Econômica dos Funcionários Públicos de Ouro Preto, fundada em outubro de I889. Essa sociedade era classificada como uma cooperativa de consumo, porém, de acordo com Pinheiro (2008, p. 27), tinha em seu estatuto artigos que previam a existência de um “[...]'caixa de auxílios e socorros' para prestação de auxílio às viúvas de associados e a sócios que caíssem na 'indigência por falta absoluta de meio de trabalho'”, que remetia às cooperativas de crédito mistas.

As cooperativas de crédito no Brasil são classificadas, de acordo com a Lei n. 5.764 (I97I), como singulares, centrais ou federações e confederações de cooperativas. As cooperativas singulares são formadas por um número mínimo de 20 associados. As centrais ou federações são constituídas por, no mínimo, três cooperativas singulares, e têm o objetivo de organizar os serviços econômicos e assistenciais das filiadas, além de integrar e orientar suas atividades. Já uma confederação de cooperativas abrange no mínimo três centrais ou federações, assim como as centrais; objetiva organizar e orientar suas afiliadas. Dentre as três classificações, apenas as centrais ou federações têm o status de instituição financeira, entretanto, as confederações de cooperativas podem obter aprovação do Banco Central para serem consideradas instituições financeiras também. 
Apesar de apresentar baixa relevância no Sistema Financeiro Nacional (SFN), as cooperativas têm apresentado crescimento contínuo de unidades, ao contrário das outras instituições que compõem o SFN. Além do crescimento em número de instituições, as cooperativas de crédito têm ganhado cada vez mais espaço nas operações de crédito, passando de 0,53\% em 1996 para 2,30\% em 2012 (Bacen, 20I3).

O ativo total das cooperativas de crédito representou, em 20I2, I,80\% do ativo total do SFN (Bacen, 20I3). Essa porcentagem equipara-se à encontrada por Wheelock e Wilson (2013) nos Estados Unidos, que era de 6\% em 2009. No tocante às operações no ano de 2012 , as cooperativas foram responsáveis por, em média, 2,7\% do total das operações de crédito realizadas no Brasil (Melo et al., 2013; Bacen, 2013).

Na literatura internacional, é possível encontrar estudos como de Goddard, McKillop e Wilson (2002), que tratam sobre diversificação de atuação e o desempenho financeiro de cooperativas de crédito nos Estados Unidos. Para as cooperativas de crédito dos Estados Unidos, a receita a partir de fontes alternativas às de intermediação financeira têm aumentado significativamente nos últimos anos. Segundo os autores, para o período de 1993-2004, impactos positivos no desempenho de grandes cooperativas de crédito estão vinculados à exploração de novas oportunidades de produtos em torno de sua principal especialidade.

A literatura que trata sobre aspectos de avaliação e desempenho econômico-financeiro de cooperativas de crédito brasileiras se mostrou reduzida. Dentre os trabalhos consultados, ressalta-se Ferreira, Gonçalves e Braga (2007), que investigaram o desempenho de cooperativas de crédito mineiras. Segundo os autores, tais cooperativas

[...] têm extensão considerável para técnica, ganhos de eficiência, principalmente em razão do grande lapso de eficiência associado à subutilização de recursos, fator que no longo prazo pode comprometer a sustentabilidade e competitividade dessas organizações (Ferreira, Gonçalves, \& Braga, 2007, p. 438).

Além disso, o estudo constatou que o maior impacto marginal sobre a eficiência técnica das cooperativas mineiras teve origem na geração de renda. Dessa forma, quanto maior a capacidade de gerar renda por meio das atividades de intermediação financeira, maiores serão os ganhos de eficiência. Nesse caso, os autores ressaltam que, tendo em vista que as cooperativas possuem um objetivo social de prover crédito em condições mais acessíveis, a maximização de suas receitas deveria ser obtida via expansão de volumes ou, pode-se supor, de rendas com prestação de serviços. 
Bressan, Lopes e Menezes (2013) avaliaram o desempenho das cooperativas de crédito filiadas ao Sistema de Cooperativas de Crédito do Brasil (Sicoob) no período de 2000 a 2008 pelo método de Análise Envoltória de Dados; para avaliar os determinantes na eficiência foi aplicada a técnica econométrica Tobit. Os resultados obtidos no estudo indicaram que o número de cooperativas eficientes durante o período de análise não ultrapassou ı०\% do total e ainda destacaram que fatores como tamanho e tempo de existência não influenciam a avaliação. Por fim, afirmaram que os fatores "Capital Institucional/Ativo Total" e "Investimentos Financeiros/Ativo Total" estão relacionados positivamente com a eficiência das cooperativas.

Bressan, Braga e Lima (2004) estudaram a insolvência das cooperativas de crédito de Minas Gerais no período de I998 a 200I por meio da estrutura financeira das entidades. Os autores afirmaram que o processo de insolvência é influenciado pelas variáveis: capitalização, cobertura voluntária, despesa administrativa e crescimento da captação total. Ainda no tocante à insolvência, Bressan, Braga, Bressan e Resende Filho (20II) aplicaram o sistema Pearls para analisar a probabilidade de insolvência das cooperativas de crédito afiliadas ao Sicoob-Crediminas no período de I995 a 2008.

Os resultados da pesquisa indicaram que quanto maiores os resultados das variáveis "operações de crédito vencidas/carteira classificada total" e "ativos não direcionados com a atividade-fim da cooperativa/ativo total", maior a probabilidade de insolvência da cooperativa, assim como as variáveis "capital institucional/ativo total" e "rendas de prestação de serviços/despesas administrativas" apresentam resultados favoráveis - quanto maior o resultado, menor o risco de insolvência.

Já a eficiência de custo e a economia de escala foram estudadas por Bressan, Braga e Bressan (20I0). Os autores analisaram 42 cooperativas de crédito mútuo no estado de Minas Gerais no período de 200I a 2003. Para estimar a eficiência de custo foi aplicada a técnica paramétrica fronteira estocástica, e para analisar a hipótese da economia de escala foi estudada a relação entre produtos e custos. Os resultados apontam alta ineficiência de custo para as cooperativas de crédito da amostra e a relação positiva da eficiência com as variáveis capital físico, produto e trabalho, assim como mostram que as cooperativas operam na faixa de economia de escala.

Dambros, Lima e Figueiredo (2009) analisaram a eficiência econômica das cooperativas de crédito no estado do Paraná nos anos de 2005 e 2006. Para tal análise foi empregada a técnica estatística análise fatorial. Os resultados do estudo sugerem que a maior parte das cooperativas apresenta-se ineficiente quando os fatores aplicação do crédito, rentabilidade econômica e liquidez são estudados em conjunto.

Bressan, Braga e Bressan (2003) analisaram as cooperativas de crédito rural de Minas Gerais no período de I998 a 200 I por meio de indicadores financeiros 
propostos pelo Manual da Austin Asis. Os indicadores foram divididos em estrutura, solvência, despesas, crescimento e rentabilidade. Utilizando a mesma metodologia, Quiroga, Bressan e Braga (2005) analisaram as cooperativas de crédito mútuo de Minas Gerais no período seguinte, de 2001 a 2003. Os resultados de ambos os estudos corroboram ao afirmar que as cooperativas estudadas têm situação financeira estável, porém destacou-se atenção especial ao acompanhamento do risco de crédito, à evolução do volume de receitas em função do número de associados e ao nível de crescimento em relação ao desempenho financeiro.

Diante de um mercado de crédito dominado pelas instituições financeiras bancárias, o cooperativismo de crédito encontra nos bancos sua principal concorrência. Tal concorrência é fator expressivo para que o desempenho financeiro das cooperativas seja foco de constante avaliação e acompanhamento. Smith, Cargill e Meyer (I98I) afirmam que apesar de as cooperativas de crédito atuarem como intermediários financeiros, elas apresentam características únicas que as diferenciam das demais instituições financeiras, como as instituições bancárias.

\subsection{O SEGMENTO BANCÁRIO}

A partir da implantação do Plano Real em I994, o setor bancário passou por uma série de mudanças, como a estabilização da inflação e dos preços, e, consequentemente, a redução dos ganhos por floating. Essas mudanças iniciaram uma série de ações por parte das instituições bancárias, que mudaram suas estratégias ao ofertar novos produtos e utilizar novas tecnologias. Contudo, foi apenas em 2003 que as instituições financeiras iniciaram as mudanças nos seus portfólios de ativo devido à certeza de que não haveria mudanças na política econômica do novo governo e da melhora em âmbito macroeconômico. A partir desse contexto os bancos notaram potencial de ganhos na oferta de crédito à pessoa física, visto que a avaliação desta é menos complicada que a avaliação das pessoas jurídicas.

De acordo com Jacob (2003), apesar de existirem diversos agentes credores em uma economia capitalista, como família e amigos, o mais comum é o empréstimo por meio de instituições financeiras. A preferência pelos empréstimos por meio de instituições financeiras se dá devido a sua capacidade de associar recursos e do alto nível de especialização nas transações.

Com base nessa afirmação, é importante observar como instituições desse tipo se comportam diante do desafio de gerenciar seus recursos, assim como recursos de terceiros.

No mercado de crédito, existe a separação entre instituições privadas e instituições públicas, e a principal diferença consiste no fato de as instituições públicas serem as instituições oficiais responsáveis por operar linhas de crédito com recursos direcionados. 
De acordo com dados do Bacen (20I3), os bancos públicos vinham perdendo espaço no mercado de crédito para os bancos privados, visto que em ig 88 o setor público detinha $66 \%$ das operações de crédito contra $34 \%$ do setor privado. Entretanto, em 2002, o quadro se inverteu e os bancos públicos passaram a representar apenas $36 \%$ e o setor privado, $64 \%$. Novamente uma mudança dessa relação foi verificada após 2008 , dados os efeitos da crise financeira norte-americana, em que grande parcela dos participantes do mercado bancário revisou suas posições (Freitas, 2009), consequentemente reestruturando a participação das instituições financeiras, enquanto as públicas voltaram a ganhar espaço, uma vez que em 2007 detinham $34,44 \%$ do total de empréstimos e em 2012 já detinham 45,55\% (Bacen, 2013).

Além da divisão entre setor privado e público, existem outras segmentações importantes na estrutura bancária brasileira. Os bancos privados podem ser divididos por porte; já o setor público está concentrado principalmente em três instituições com objetivos distintos. O Banco Nacional de Desenvolvimento Econômico e Social (BNDES) é a principal instituição de crédito de longo prazo, atuando como impulsionador de desenvolvimento. A Caixa Econômica Federal (CEF) atua principalmente no setor habitacional e de desenvolvimento urbano. Por fim, o Banco do Brasil (BB) é o maior banco existente no país, detentor de I $8,2 \%$ do ativo total do setor, segundo dados de dezembro de 2012 do Bacen (2013). O BB ainda concentra suas atividades na concessão de crédito tanto ao setor público quanto privado, além de ser utilizado como um dos principais instrumentos do governo federal nas políticas agrícolas.

\subsection{INDICADORES DE ANÁLISE FINANCEIRA}

Para garantir a continuidade das empresas, é importante que a gestão de seus recursos seja feita de maneira eficiente, pois com os avanços da tecnologia e a globalização, os mercados têm se tornado cada vez mais competitivos.

Segundo Ceretta e Niederauer (200I), a eficiência operacional investiga o desempenho relacionado à combinação de recursos para obtenção de receitas. Apergis e Alevizopoulou (20II) assumem que uma entidade financeira é eficiente caso ela aplique uma quantia correta de insumos para convertê-la em produtos financeiros e serviços. Assaf Neto (2000) ressalta que o índice de eficiência operacional é um dos mais utilizados na avaliação de instituições bancárias por relacionar as despesas operacionais com as receitas de intermediação financeira. Dias (20II) apresenta o conceito de eficiência produtiva como a capacidade de produzir mais produtos com a mesma quantidade de insumos, evitando desperdícios.

Bressan et al. (20II), em seu estudo sobre a insolvência das cooperativas de crédito do estado de Minas Gerais, aplicaram as rendas de prestação de serviço 
no cálculo do índice de eficiência e concluíram que quanto maior este índice, menor será a probabilidade de insolvência da entidade.

As variáveis que determinam o cálculo do índice de eficiência são influenciadas por choques de mercado: por exemplo, uma queda na taxa de juros ou dados publicados pelo Bacen sobre o comportamento da inadimplência. Esses choques alteram diretamente a postura dos agentes econômicos presentes no mercado de crédito.

No sentido de complementar a análise do indicador de eficiência, o presente estudo adotou o uso da análise financeira relativa. Assim, com a análise conjunta do indicador de eficiência e a elucidação da trajetória tanto de evolução (crescimento, decrescimento, manutenção) quanto de importância na estrutura patrimonial e na formação de resultado, busca-se uma avaliação constituída por relações e interações. Nesse sentido, dado o indicador de eficiência, o uso adicional da análise relativa pode fornecer informações importantes e críticas sobre o desempenho e a situação das instituições (Matias, 2009).

O montante de uma conta ou grupo de contas do balanço patrimonial, se analisado de maneira individual, não demonstra a real importância ou comportamento ao decorrer do tempo, portanto, é necessária a comparação entre os dados correntes e os dados de períodos anteriores. A comparação entre períodos oferece um aspecto ilustrativo e dinâmico da situação patrimonial da instituição (Assaf Neto, 2000; Matias, 2009).

Para compreender a importância de uma conta em relação a um grupo patrimonial e identificar tendências, podem-se aplicar as técnicas de análise horizontal e vertical, foco da análise financeira relativa.

Para Assaf Neto (2000), análise horizontal é a comparação feita entre valores da mesma conta ou grupo de contas em diferentes exercícios sociais, ou seja, é uma análise temporal baseada em números índices. Matias (2009) afirma que, a partir da comparação entre os valores atuais com os valores corrigidos de períodos anteriores, é possível observar a evolução dessa conta; Matarazzo (2003) complementa esse pensamento afirmando que a análise horizontal baseia-se na evolução de cada conta, e que essa evolução demonstra possíveis tendências da empresa.

Matarazzo (2003) argumenta que o objetivo da análise vertical é demonstrar a importância de cada conta das demonstrações contábeis e, por meio da comparação com índices padrão, seja do setor ou da própria empresa em períodos diferentes, verificar se há itens em proporções anormais. Assaf Neto (2000) afirma que a análise vertical é um processo comparativo expresso em percentagem que possibilita apurar a participação relativa de uma conta no demonstrativo financeiro da entidade por meio da relação da conta com um valor afim no mesmo demonstrativo. Segundo Matias (2009), na análise vertical o principal ponto a ser analisado é o comportamento relativo da conta em relação ao parâmetro anteriormente definido, ou seja, sua evolução temporal. 
A comparação direta entre bancos e cooperativas de crédito poderia ser vista como equivocada, pois, de acordo com Smith (I986), ao contrário das instituições bancárias, as cooperativas de crédito não visam a maximização dos lucros. Contudo, Hendriksen e Breda (20II, p. I04) argumentam que "é lógico reconhecer que a entidade deveria ser vista como se permanecesse em operação indefinidamente, em condições normais", portanto, é possível assumir que todas as entidades, independentemente do objetivo social, visam a obtenção de resultados para sua sobrevivência. Dessa forma, podem-se diferenciar as entidades do terceiro setor - cooperativas de crédito - das entidades do segundo setor - instituições bancárias - não pela obtenção de resultados e sim pela maneira como esses resultados serão distribuídos (Fernandes, I997).

A comparação entre ambos os segmentos pelos mesmos indicadores, portanto, pode ser corroborada por toda a literatura apresentada, uma vez que foi possível depreender que variáveis como geração de rendas (por intermediação financeira ou por prestação de serviços), despesas estruturais (administrativas e de pessoal) possuem alta relevância para a obtenção de resultados tanto de cooperativas de crédito quanto de instituições financeiras bancárias.

No tocante à prestação de serviços, Fried, Lovell e Eeckaut (I993) destacam a importância da prestação de serviços ao afirmarem que o objetivo principal da cooperativa é a maximização dos serviços aos seus membros. Assaf Neto (20I4) corrobora essa afirmação ao argumentar que as cooperativas de crédito operam predominantemente com as operações de crédito e de prestação de serviços. A importância das receitas de prestação de serviços no desempenho das cooperativas, segundo Bressan et al. (20II), reside no fato de que quanto maior a relação entre prestação de serviços e despesas administrativas, maior é a eficiência da instituição, dessa forma justificando o uso de ambas no presente estudo.

\section{METODOLOGIA}

O presente estudo apresenta caráter descritivo e tem como objetivo comparar as instituições bancárias às cooperativas de crédito.

A coleta dos dados foi realizada no site do Bacen (2013) na seção "Informações cadastrais e contábeis", visto que no site são disponibilizadas as demonstrações contábeis das instituições que formam o Sistema Financeiro Nacional.

Para as cooperativas de crédito foram analisados os balancetes de verificação, demonstrativos que relacionam as contas contábeis e seus respectivos saldos, referentes aos meses de junho e dezembro, por serem saldos acumulados semestrais. A análise por meio dos balancetes foi empregada pois, ao contrário 
das instituições bancárias, as cooperativas de crédito não divulgam as demonstrações contábeis completas - balanço patrimonial, demonstração de resultado do exercício, demonstração do fluxo de caixa, demonstração do valor adicionado, demonstração das mutações do patrimônio líquido e notas explicativas.

Para as instituições bancárias foram analisados os balanços patrimoniais, demonstração de resultado do exercício e notas explicativas.

Para fins comparativos, foram calculados os índices de eficiência (Equação I) adotados por Matias (I999) tanto para as instituições bancárias quanto para as cooperativas de crédito. $\mathrm{O}$ indicador de eficiência foi calculado por meio do Resultado Bruto de Intermediação Financeira (RBIF), somado às Perdas Estimadas com Clientes de Liquidação Duvidosa (PECLD) e às Receitas de Prestação de Serviços sobre as Despesas Estruturais (despesas administrativas mais despesas de pessoal). Este indicador demonstra quanto de receita é gerada para cada real de despesa; logo, quanto maior o índice, maior a eficiência econômica da instituição.

$$
\text { Eficiência }=\frac{R B I F+\text { PECLD }+ \text { Receita de Prestação de Serviços }}{\text { Despesas Administrativas e de Pessoal }}
$$

Para aplicação do índice nas cooperativas de crédito foram feitas as seguintes adaptações: as contas "despesas de pessoal" e "outras despesas administrativas" foram substituídas pelas contas "despesas administrativas" e "despesas não operacionais" por representarem a mesma natureza de informações. As adaptações foram necessárias devido à impossibilidade de identificar as contas contábeis de despesas e receitas nos balancetes de verificação divulgados pelo Bacen. Essa impossibilidade de identificar as contas é tida como uma das limitações da pesquisa, mas que não prejudicou as análises, uma vez que foi possível constatar a assertividade dos valores encontrados na conferência pelos dados divulgados por algumas cooperativas.

Além da análise do índice de eficiência, foram analisadas as evoluções horizontal e vertical da renda de prestação de serviços de ambos os segmentos estudados. A escolha dessa conta deve-se à sua importância no desempenho das instituições evidenciada pelo referencial teórico apresentado.

Com base nos dados obtidos (índice de eficiência e evolução da receita de prestação de serviços), foi aplicado o teste não paramétrico Kruskal-Wallis para verificar a existência de diferença entre os três grupos estudados - cooperativas de crédito, bancos públicos e bancos privados. Para essa fase foi utilizado o programa estatístico Software Action versão 2.4.I63.322, o qual opera em plataforma $\mathrm{R}^{\mathrm{I}}$. Conforme 
resultados do teste apresentados na Tabela 2, existem evidências suficientes para rejeitar a hipótese nula de que todas as populações têm funções de distribuição iguais.

\section{TABELA 2}

RESULTADOS DO TESTE DE KRUSKAL-WALLIS DO ÍNDICE

DE EFICIÊNCIA E RECEITA DE PRESTAÇÃO DE SERVIÇOS BANCOS PÚBLICOS, PRIVADOS E COOPERATIVAS

DE CRÉDITO - 2002 A 2012

\begin{tabular}{lcc}
\hline INFORMAÇÃO & EFICIÊNCIA & PRESTAÇÃO DE SERVIÇOS \\
\hline Kruskal-Wallis qui-quadrado & 28,24180461 & 94,6661 \\
\hline Graus de liberdade & 2 & 2 \\
\hline P-valor & $7,36835 E-07$ & $2,77649 \mathrm{E}-21$ \\
\hline
\end{tabular}

Fonte: Elaborada pelos autores.

O período de análise compreende dez anos, de 2002 a 20I2, assim é possível obter uma análise temporal significativa e que contempla mudanças e acontecimentos importantes no mercado de atuação dos segmentos analisados.

A amostra foi selecionada de acordo com o critério "Total do Ativo". As instituições foram ranqueadas da maior para a menor com base nesse critério e, com base nesse ranking, selecionou-se a amostra do conjunto com participação superior a $60 \%$. Nas instituições bancárias, a média da amostra foi de 69,31\% (média de seis instituições) e nas cooperativas de crédito, a média foi de 6I,30\% (média de 220 instituições).

\section{ANÁLISE dOS RESULtAdOS}

Neste tópico serão discutidos os resultados encontrados no estudo e serão apresentados os gráficos e tabelas decorrentes destes.

\section{ANÁLISE DO INDICADOR DE EFICIÊNCIA}

Para definir a estatística descritiva a ser utilizada nas comparações, foram calculadas as medidas de posição e dispersão apresentadas na Tabela 3. Constatou-se que a média seria uma informação relevante apenas se a análise compreendesse 
o segmento das instituições bancárias, já que, no caso do segmento cooperativista, os dados apresentaram grandes oscilações.

O coeficiente de variação (CV) para os dados dos bancos públicos e privados situou-se abaixo de o,2; já o CV das cooperativas de crédito situou-se acima de 0,4 . Também é possível notar, pelas medidas de mínimo e máximo, maior dispersão nos dados das cooperativas do que nos dados dos bancos. Tendo em consideração tal análise, optou-se pelo uso da mediana para realizar as análises que se seguem. O uso da mediana é indicado quando os dados apresentam valores extremos e, de acordo com Kazmier (2007, p. 54), "a mediana é sempre uma excelente medida que representa o nível 'típico' dos valores observados [...]”.

\section{TABELA 3}

ESTATISTICA DESCRITIVA DOS ÍNDICES DE EFICIÊNCIA, BANCOS PÚBLICOS, PRIVADOS E COOPERATIVAS

DE CRÉDITO - 2002 A 2012

\begin{tabular}{|c|c|c|c|c|c|c|c|c|c|c|c|c|}
\hline & GRUPO/ESTATÍSTICA & 2002 & 2003 & 2004 & 2005 & 2006 & 2007 & 2008 & 2009 & 2010 & 2011 & 2012 \\
\hline \multirow{6}{*}{ 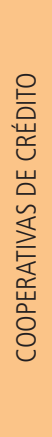 } & Média & 1,7 & 1,85 & 1,69 & 1,79 & 1,82 & 1,92 & 2,2 & 2,2 & 1,94 & 1,94 & 2,42 \\
\hline & Mediana & 1,51 & 1,62 & 1,45 & 1,59 & 1,59 & 1,65 & 1,72 & 2,08 & 1,83 & 1,71 & 2,19 \\
\hline & Desvio padrão & 0,98 & 1,31 & 0,92 & 0,96 & 0,93 & 1,15 & 2,13 & 0,92 & 0,91 & 1,17 & 0,95 \\
\hline & $\begin{array}{l}\text { Coeficiente de } \\
\text { variação }\end{array}$ & 0,58 & 0,71 & 0,54 & 0,54 & 0,51 & 0,60 & 0,97 & 0,42 & 0,47 & 0,60 & 0,39 \\
\hline & Máximo & 5,75 & 9,4 & 8,01 & 6,97 & 6,95 & 10,58 & 22,12 & 9,95 & 7,51 & 14,59 & 6,28 \\
\hline & Mínimo & $-0,21$ & $-1,04$ & $-0,03$ & $-0,23$ & $-0,29$ & $-1,7$ & $-0,39$ & $-0,52$ & $-1,64$ & $-0,11$ & 0,41 \\
\hline \multirow{6}{*}{ 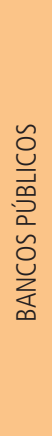 } & Média & 1,78 & 1,9 & 1,78 & 1,86 & 1,92 & 1,74 & 1,77 & 1,84 & 1,94 & 2,04 & 1,91 \\
\hline & Mediana & 1,61 & 1,87 & 1,72 & 1,82 & 1,95 & 1,79 & 1,73 & 1,91 & 1,99 & 2,12 & 1,93 \\
\hline & Desvio padrão & 0,3 & 0,25 & 0,28 & 0,23 & 0,24 & 0,22 & 0,2 & 0,19 & 0,24 & 0,23 & 0,09 \\
\hline & $\begin{array}{l}\text { Coeficiente de } \\
\text { variação }\end{array}$ & 0,17 & 0,13 & 0,16 & 0,12 & 0,13 & 0,13 & 0,11 & 0,10 & 0,12 & 0,11 & 0,05 \\
\hline & Máximo & 2,13 & 2,16 & 2,09 & 2,11 & 2,15 & 1,93 & 1,98 & 1,98 & 2,15 & 2,21 & 1,98 \\
\hline & Mínimo & 1,6 & 1,66 & 1,54 & 1,65 & 1,66 & 1,5 & 1,59 & 1,63 & 1,68 & 1,78 & 1,81 \\
\hline
\end{tabular}

(continua) 
TABela 3 (CONClusão)

ESTATISTICA DESCRITIVA DOS ÍNDICES DE EFICIÊNCIA, BANCOS PÚBLICOS, PRIVADOS E COOPERATIVAS

DE CRÉDITO - 2002 A 20I2

\begin{tabular}{|c|c|c|c|c|c|c|c|c|c|c|c|c|}
\hline & GRUPO/ESTATISTICA & 2002 & 2003 & 2004 & 2005 & 2006 & 2007 & 2008 & 2009 & 2010 & 2011 & 2012 \\
\hline \multirow{6}{*}{ 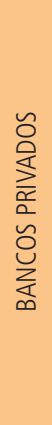 } & Média & 1,93 & 1,98 & 2,05 & 2,29 & 2,41 & 2,52 & 2,17 & 2,52 & 2,33 & 2,41 & 2,42 \\
\hline & Mediana & 1,95 & 1,86 & 1,92 & 2,36 & 2,43 & 2,46 & 2,16 & 2,37 & 2,26 & 2,32 & 2,3 \\
\hline & Desvio padrão & 0,05 & 0,26 & 0,27 & 0,28 & 0,23 & 0,16 & 0,19 & 0,39 & 0,18 & 0,17 & 0,22 \\
\hline & $\begin{array}{l}\text { Coeficiente de } \\
\text { variação }\end{array}$ & 0,03 & 0,13 & 0,13 & 0,12 & 0,10 & 0,06 & 0,09 & 0,15 & 0,08 & 0,07 & 0,09 \\
\hline & Máximo & 1,97 & 2,27 & 2,36 & 2,53 & 2,63 & 2,7 & 2,36 & 2,97 & 2,53 & 2,61 & 2,67 \\
\hline & Mínimo & 1,87 & 1,8 & 1,86 & 1,99 & 2,17 & 2,41 & 1,98 & 2,22 & 2,19 & 2,3 & 2,29 \\
\hline
\end{tabular}

Fonte: Elaborada pelos autores com dados das instituições.

Os resultados obtidos a partir da aferição das medianas do índice de eficiência indicaram algumas mudanças nos segmentos analisados. Pode-se observar no Gráfico I que os bancos privados analisados mantiveram índice de eficiência crescente, durante quase todo o período, apresentando apenas três momentos de queda: em 2003, I,86; em 2008, 2,16; e em 2010, 2,26.

\section{GRÁFICO I}

MEDIANA DOS ÍNDICES DE EFICIÊNCIA, BANCOS PÚBLICOS, PRIVADOS E COOPERATIVAS DE CRÉDITO - 2002 A 2012

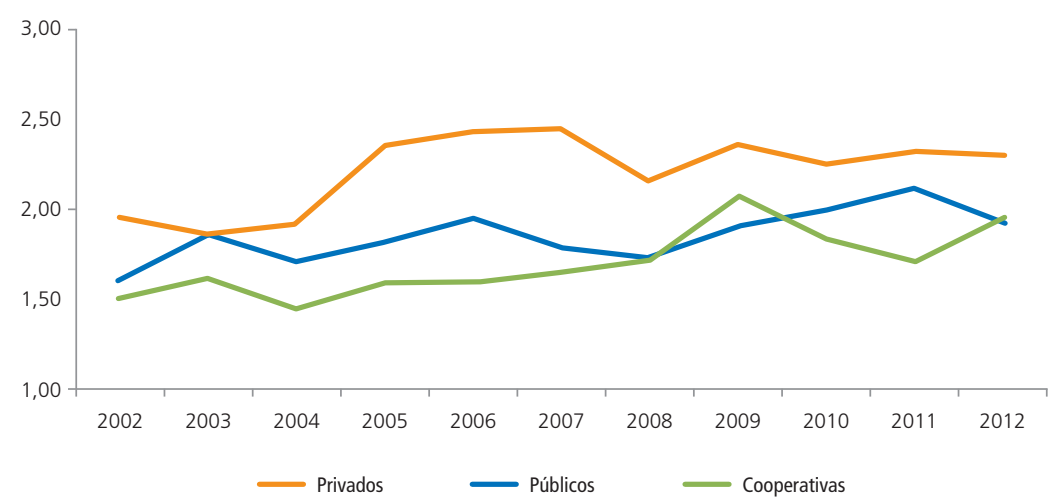

Fonte: Elaborado pelos autores com dados das instituições. 
Os bancos públicos também registraram algumas oscilações, com elevações e quedas no período de análise, porém, nota-se que em 2007 e 2008 alcançaram os menores índices, I,79 e I,73, em relação ao próprio desempenho em outros anos. Já as cooperativas de crédito registraram uma elevação significativa no índice, principalmente a partir de 2007, I,65, e em 2009, ano em que ultrapassaram o índice alcançado pelo segmento de bancos públicos, respectivamente 2,08 e I,9I. Apesar da queda no indicador das cooperativas em 20II, logo em 2012 nota-se uma recuperação e aproximação ao registrado pelos bancos públicos.

No sentido de compreender os movimentos registrados, foram analisadas as contas que compõem o índice de eficiência. Ao analisar a participação das despesas estruturais no resultado bruto da intermediação financeira (RBIF), Gráfico 2, nota-se que o segmento de bancos privados registrou uma elevação do comprometimento do RBIF com as despesas estruturais. No período até 2007 , os bancos privados registravam o menor nível de comprometimento das despesas estruturais, média de 0,89 . A partir de 2008 , entretanto, essa relação sofre uma alta que perdura até 20IO, com pico em 2008 de I,3I. Após 20II, O indicador retorna ao nível anterior, porém com tendência de alta.

Essa elevação em 2008 fez com que o comprometimento do resultado com despesas dos bancos privados fosse maior do que o verificado nas cooperativas e bancos públicos. Em praticamente todo o período de análise, os bancos públicos apresentaram o maior comprometimento do resultado com as despesas estruturais - para cada $R \$$ I,, 0 de resultado, as despesas estruturais corresponderam em média a R \$ I,I5. A partir de 2007 a relação aumenta, chegando a R \$ I,34 em 20II. É perceptível que o indicador não retomou o nível abaixo de I,०o registrado antes de 2007, mantendo-se acima de I,20 no restante do período (Gráfico 2).

\section{GRÁFICO 2}

RELAÇÃO ENTRE DESPESAS ESTRUTURAIS/RESULTADO BRUTO DE INTERMEDIAÇÃO FINANCEIRA - BANCOS PÚBLICOS, PRIVADOS E COOPERATIVAS DE CRÉDITO - 2002 A 2012

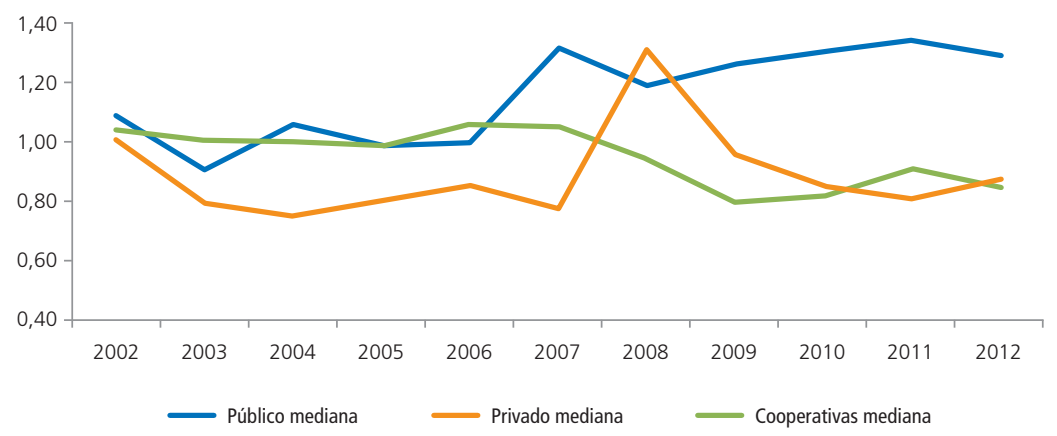

Fonte: Elaborado pelos autores com dados das instituições. 
Já as cooperativas de crédito no período até 2007 apresentaram grau de comprometimento das despesas estruturais em relação ao RBIF similar ao dos bancos públicos e acima dos bancos privados, 0,95. Após 2007, além do efeito da elevação do indicador nos bancos privados, as cooperativas registraram queda, entre 2008 e $2010,0,87$. Já a partir de 20 io, as cooperativas registraram manutenção desse indicador. No segmento cooperativista, nota-se que a queda no indicador pode ter sido um dos principais motivos para o aumento da eficiência desse segmento (Ferreira, Gonçalves, \& Braga, 2007).

Quando se analisa a participação das despesas estruturais na receita de prestação de serviços, Gráfico 3, nota-se que esse tipo de receita foi uma importante fonte de recursos para equilibrar a eficiência dos segmentos analisados. Isso porque o indicador apresentou queda e/ou manutenção para todos os segmentos, indicando controle das despesas estruturais e elevação das receitas de prestação de serviços tanto para as cooperativas quanto para os bancos.

No período até 2007 , tal indicador nas cooperativas de crédito, 5,48, é significativamente maior do que o apurado nos outros segmentos, abaixo de 2,00. Conforme demonstrado no Gráfico 3, a relação apresentou trajetória de queda, principalmente até 2007 , alcançando média de 4,63 , porém registrando ligeira alta, 4,20, em 20I2. Retomando as concepções de Ferreira, Gonçalves e Braga (2007), ratifica-se que a geração de rendas por serviços representa um importante fator para melhorar a eficiência e ao mesmo tempo promover o objetivo das cooperativas sem sobrepujar os elementos de intermediação financeira. Além disso, a exploração de novas oportunidades de produtos parece contribuir para impactos positivos no desempenho dessas instituições (Goddard, McKillop, \& Wilson, 2002).

No caso dos bancos públicos, até 2010 , a cada $\mathrm{R} \$$ I,०० de receita com prestação de serviços, as despesas estruturais correspondiam à média de R \$ I,76. A partir de 20II, essa relação caiu para a média de R\$ I,49. Entre 2010 a 20I2, esteve similar aos bancos privados. Estes, em toda a série, apresentaram o menor nível, média de I,45, e entre 2010 e 2012 registrou-se um pouco acima dos bancos públicos, média de $\mathrm{R}$ I,54 (Gráfico 3).

Por fim, cabe destacar que no caso da PCLD, como é uma provisão e para que se possa ter uma interpretação financeira, no índice soma-se esta ao RBIF. Com isso é possível ter uma ideia do RBIF na visão financeira para fazer frente às despesas estruturais. Por esse motivo, a análise separada desta conta não é necessária, tendo em vista o papel de recomposição da RBIF em vez de uma conta com efeito direto no índice de eficiência utilizado. 
GRÁFICO 3

RELAÇÃO ENTRE DESPESAS ESTRUTURAIS/RECEITA DE PRESTAÇÃO DE SERVIÇOS - BANCOS PÚBLICOS, PRIVADOS

E COOPERATIVAS DE CRÉDITO - 2002 A 2012

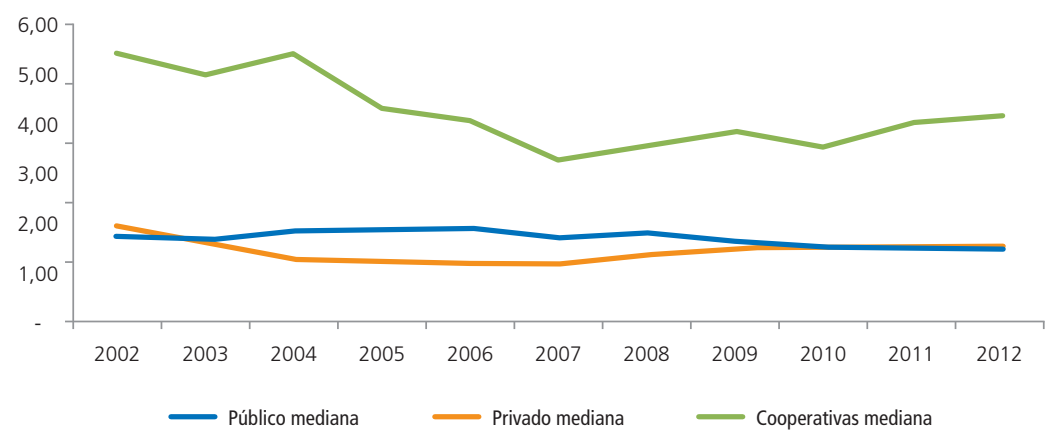

Fonte: Elaborado pelos autores com dados das instituições.

\subsection{RECEITAS DE PRESTAÇÃO DE SERVIÇOS}

Da mesma forma feita no subitem anterior, neste, para se definir a estatística descritiva a ser utilizada nas comparações, foram calculadas as medidas de posição e dispersão apresentadas na Tabela 4. Nesse caso, constatou-se que a média não seria a medida mais indicada para os segmentos estudados. Tanto o CV quanto as medidas de mínimo e máximo destacam a ocorrência de valores extremos, indicando, assim, o uso da mediana.

Como foi possível identificar na literatura, as receitas de prestação de serviços apresentaram-se relevantes no contexto de eficiência dos segmentos analisados, principalmente para as cooperativas de crédito. Para confirmar o comportamento desse tipo de receitas, mostram-se relevantes as análises horizontal e vertical de tal conta.

A evolução horizontal das receitas medianas de prestação de serviços é apresentada no Gráfico 4. É perceptível que o segmento das cooperativas de crédito registrou os maiores percentuais de crescimento, média de $18,3 \%$, com pico de alta em $2005,55,9 \%$, e decréscimos apenas em 2008 e 20 II, respectivamente $0,16 \%$ e $0,93 \%$. 


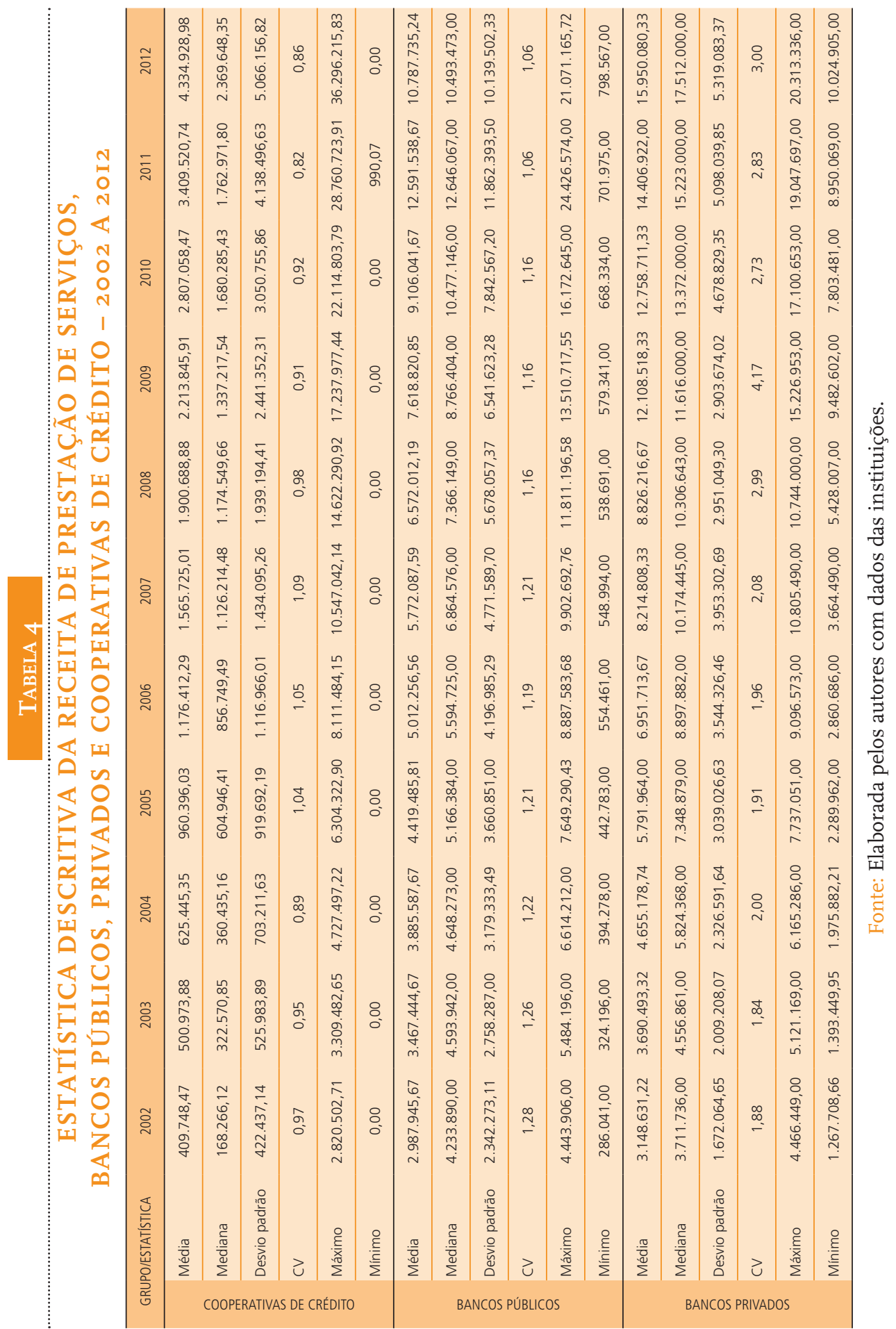


Os bancos privados registravam certa manutenção até 2007, média de I3,7\%. Em 2008 registrou decréscimo de 3,03\% e, a partir desse ano, apresentou tendência de recuperação aos percentuais apresentados na pré-crise (Gráfico 4). Já os bancos públicos apresentaram uma trajetória inconstante, com pico de alta em $2007,18,9 \%$, queda em $2008,2,73 \%$, recuperação entre 2009 e 20II, média de $13,6 \%$, mas significativo decréscimo em 20I2, -22\% (Gráfico 4).

GRÁFICO 4

EVOLUÇÃO HORIZONTAL DAS RECEITAS DE PRESTAÇÃO

DE SERVIÇOS - BANCOS PÚBLICOS, PRIVADOS

E COOPERATIVAS DE CRÉDITO - 2002 A 2012

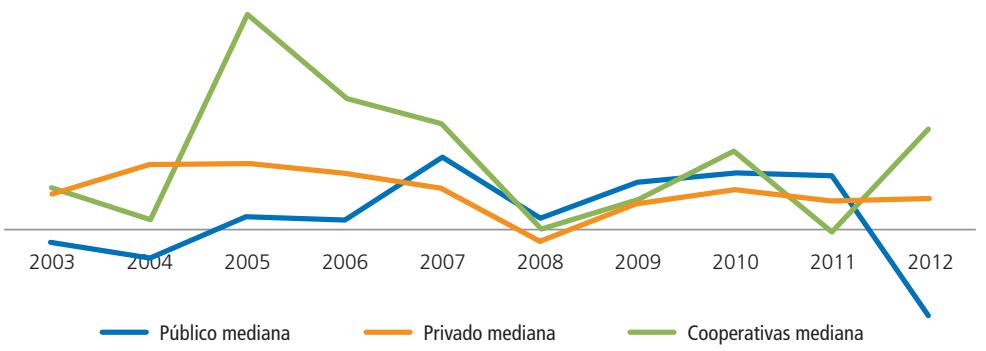

Fonte: Elaborado pelos autores com dados das instituições.

No que concerne à análise vertical das receitas médias de prestação de serviços, é possível notar, no Gráfico 4, uma convergência nas participações de cada segmento analisado. A participação das receitas de prestação de serviços no total das receitas (receitas de intermediação financeira somadas às receitas de prestação de serviços) mostrou-se, no último ano de análise, mais próxima entre os segmentos.

No caso das cooperativas de crédito, a participação, que era de 8,5\% em 2002, alcançou o percentual de II,9\% em 20I2. Os bancos públicos, que já registravam participação de I9,7\% em 2002, mantiveram o percentual em I9,6\% em 2012. Já os bancos privados apresentaram comportamento diferenciado. Entre os anos de 2003 e 2007 apresentou o maior percentual de participação das receitas de prestação de serviços no total das receitas, média de 2I,6\%. A partir de 2008, tal participação registrou queda e manteve média de 15,3\% (Gráfico 5).

Dessa forma, é possível constatar que nos segmentos de bancos públicos e cooperativas, as tarifas cobradas pela administração de recursos, por serviços de conta corrente, pela emissão de cartões de crédito, por operações de crédito e garantias prestadas, por serviços de recebimentos ou por outros serviços 
prestados aos clientes evoluíram de maneira expressiva nos últimos anos. No caso específico das cooperativas, essa evolução é importante, pois, conforme indicado na literatura, reflete no desempenho da entidade e sustenta seu objetivo social.

Em relação aos bancos privados, entende-se que a crise verificada em 2008 pode ter sido um elemento importante para reduzir a participação desse tipo de receita e possibilitar uma adequação desse segmento aos demais analisados.

GRÁFICO 5
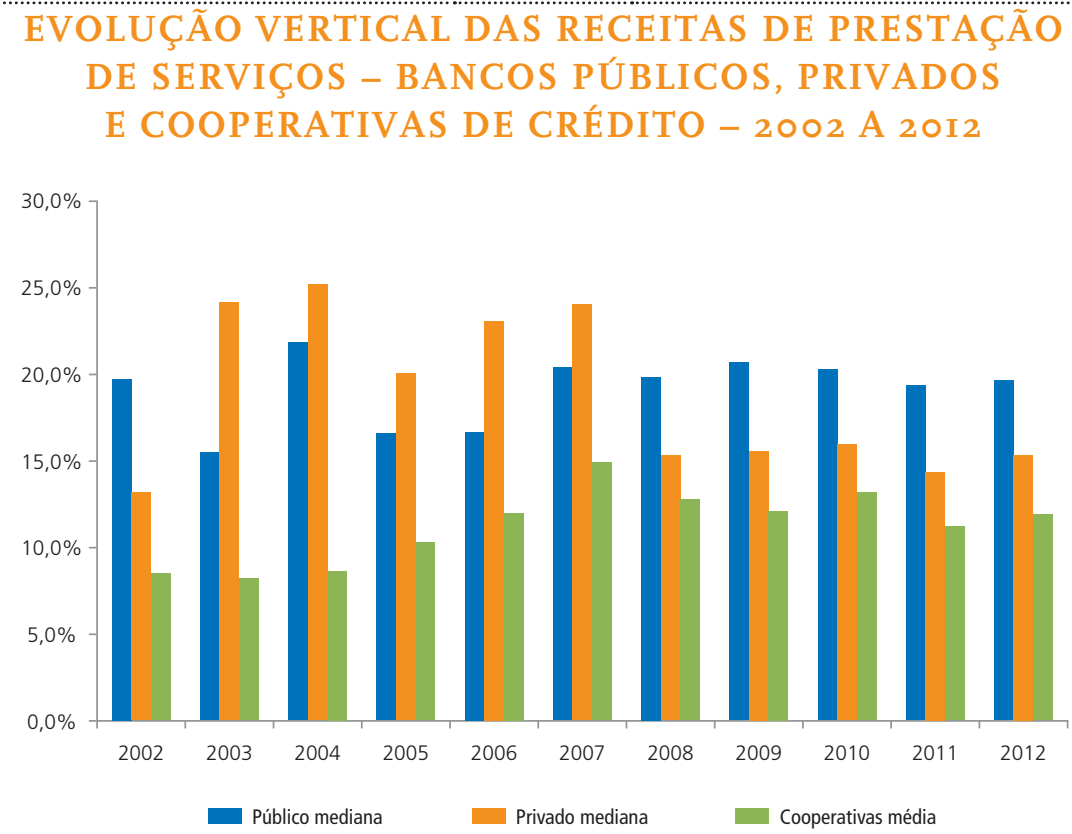

Fonte: Elaborado pelos autores com dados das instituições.

\section{CONSIDERAÇÕES FINAIS}

O presente estudo permitiu a análise de desempenho dos principais agentes do mercado de crédito brasileiro, em termos de eficiência, evolução horizontal e vertical das receitas de prestação de serviços.

No estudo do índice de eficiência, os bancos privados apresentaram os maiores níveis entre os segmentos analisados, seguidos pelos bancos públicos e, por fim, pelas cooperativas de crédito. A predominância dos bancos privados não foi abalada nos anos de crise, ao contrário dos bancos públicos, que foram ultrapassados pelo segmento cooperativista de crédito nos anos de 2008, 2009 e 2012. 
Ao decompor as contas que formam o índice, constatou-se que, até 2006 , o comprometimento do RBIF com as despesas estruturais nas cooperativas foi semelhante ao verificado nos bancos públicos, porém maior do que o dos bancos privados. Tal comportamento se diferenciou entre os anos de 2007-2010 e 20I2, quando esse indicador apresentou queda significativa no segmento cooperativista. Esse fato corrobora a percepção de que as cooperativas ganharam espaço no momento em que o mercado bancário tradicional acomodava-se aos choques das crises internacionais (Freitas, 2009).

Já com relação às receitas de prestação de serviços ante as despesas estruturais, verificou-se que a melhora no indicador de cobertura pode ter sido essencial para sustentar a eficiência dos segmentos analisados. Nesse sentido, considerando as evoluções horizontal e vertical, verificou-se que, apesar do crescimento significativo registrado pelas cooperativas de crédito e da convergência no grau de participação entre os seguimentos, a participação desse tipo de receitas ainda é maior no segmento bancário do que no cooperativista de crédito, o que pode representar um elemento de potencialidade ainda a ser explorado pelas cooperativas na busca pela eficiência.

\section{BANKS VERSUS CREDIT COOPERATIVES:}

\section{AN ANALYSIS OF THE EFFICIENCY RATIOS AND REVENUES FROM SERVICE PROVISION BETWEEN}

\section{AND 2012}

\section{ABSTRACT}

The objective in this descriptive study is to analyze the efficiency ratio and evolution in the revenues from credit cooperatives' service provision in comparison with private and public banking institutions. According to data from the Brazilian Central Bank, in 20I2, the GDP/credit index corresponded to 55.5\%, which cannot be compared yet with that of developed countries, where the ratio surpasses Io०\%. The sample includes the largest banks and cooperatives, selected based on their "total assets", totaling an average $69.31 \%$ for the banks and 6I.33\% for the credit cooperatives. To analyze the variables, efficiency ratios and vertical and horizontal analysis of the revenues from service provision were used for the period between 2002 and 20I2. The efficiency ratio is an important indicator, as it relates the inputs applied in the production with the products obtained in that process. The analysis of the revenues from service delivery is significant, demonstrating increasing relevance in financial institutions' finan- 
cial performance. The obtained results demonstrated that the private banks' efficiency ratios are the highest among the segments analyzed, followed by the public banks and, finally, by the credit cooperatives. The predominance of the private banks was not affected by the crisis years, as opposed to the public banks, which were bypassed by the cooperative segment in the years 2008-2009 and 20I2. In view of the accounts that constitute the ratio, it was verified that until 2006 the commitment of the Gross Income from Financial Intermediation to the structural expenses in the cooperatives was similar to the public banks, but higher than in the private banks. This behavior only differed in 2007-2010 and 20I2, which this indicator only dropped in the cooperative segment. In the horizontal and vertical evolutions, it was verified that, despite the significant growth registered by the credit cooperatives and the convergence in the degree of participation among the segments, the share of the revenues from service provision remains higher in the banking than in the credit cooperative segment. This fact may represent a potential element for the cooperatives to explore in the search for efficiency.

\section{KEYWORDS}

Efficiency. Banks. Credit cooperatives. Revenues from service provision. Credit market.

\section{BANCOS VERSUS COOPERATIVAS DE CRÉDITO: UN ANÁLISIS DE LOS ÍNDICES DE EFICIENCIA E INGRESOS DE PRESTACIÓN DE SERVICIOS EN EL PERÍODO DE 2002 A 2012}

\section{RESUMEN}

El presente estudio tiene carácter descriptivo y visa analizar el índice de eficiencia y la evolución de los ingresos de prestación de servicios de las cooperativas de crédito en comparación a las instituciones bancarias privada y públicas. Según datos del Banco Central de Brasil, la relación PIB/crédito correspondió al 55,5\% en 2012 , pero todavía no se compara a países desarrollados, en donde alcanza niveles superiores al ı००\%. La muestra abarca las mayores instituciones bancarias y cooperativistas, seleccionadas según el criterio "activo total", totalizando un promedio del $69,31 \%$ para las instituciones bancarias y $61,33 \%$ para las cooperativas de crédito. Para analizar las variables fueron usados índices de eficien- 
cia, análisis vertical y horizontal de los ingresos de prestación de servicio en el período entre 2002 y 2012 . El índice eficiencia es un indicador importante, ya que relaciona los insumos aplicados en la producción y los productos alcanzados en ese proceso. El análisis de los ingresos con prestación de servicios es significativo, ya que se ha mostrado cada vez más relevante en el desempeño financiero de las instituciones financieras. Los resultados alcanzados demostraron que los índices de eficiencia de los bancos privados mostraron los mayores niveles entre los segmentos analizados, seguidos por los bancos públicos y finalmente por las cooperativas de crédito. La predominancia de los bancos privados no fue afectada por los años de crisis, al contrario de los bancos públicos que fueron ultrapasados por el segmento cooperativista de crédito en los años 2008-2009 y 2012. Ante las cuentas que constituyen el índice, se constató que el comprometimiento del Resultado Bruto de la Intermediación Financiera con los gastos estructurales en las cooperativas es similar el verificado en los bancos públicos, pero es mayor que él de los bancos privados. Este comportamiento solamente fue diferente en 2007-2010 y 2012, cuando tal indicador mostró caída solamente en el segmento cooperativista. En las evoluciones horizontal y vertical, se verificó que, a pesar del crecimiento significativo registrado por las cooperativas de crédito y de la convergencia en el grado de participación entre los seguimientos, la participación de los ingresos de prestación de servicio sigue mayor en el segmento bancario que en el cooperativista de crédito. Ese hecho puede representar un elemento de potencialidad a ser explorado por las cooperativas en la búsqueda por la eficiencia.

\section{PALABRAS CLAVE}

Eficiencia. Bancos. Cooperativas de crédito. Ingresos de prestación de servicios. Mercado de crédito.

\section{REFERÊNCIAS}

Apergis, N., \& Alevizopoulou, E. (20II). Bank efficiency: Evidence from a panel of European banks. Panoeconomicus, 58(3), 329-34I. doi:Io.2298/PANiı3329A.

Assaf Neto, A. (2000). Estrutura e análise de balanços (5a ed., p. 296). São Paulo: Atlas.

Assaf Neto, A. (20I4). Mercado financeiro (I2a ed., p. 38I). São Paulo: Atlas.

Banco Central do Brasil. (20I3). Política monetária e operações de crédito do Sistema Financeiro Nacional. Recuperado em I8 setembro, 20I3, de http://www.bcb.gov.br/?ECOIMPOM.

Banco Central do Brasil. (2013). Economia e finanças: séries temporais. Recuperado em 25 outubro, 2013, de https://www3.bcb.gov.br/sgspub/localizarseries/localizarSeries.do?method=prepararTel aLocalizarSeries. 
Banco Central do Brasil. (2013). Indicadores de conjuntura. Recuperado em 25 outubro, 20I3, de http://www.bcb.gov.br/?INDECO.

Bressan, V. G. F., Braga, M. J., \& Bressan, A. A. (2003). Avaliação financeira das cooperativas de crédito rural do estado de Minas Gerais, Resumo. Financial analysis of agricultural credit cooperatives in Minas Gerais, Abstract. Revista de Administração da Ufla, 5(2), 2I-35.

Bressan, V. G. F., Braga, M. J., \& Bressan, A. A. (20I0). Eficiência e economia de escala em cooperativas de crédito: uma abordagem de fronteira estocástica de custo com dados em painel. Advances in Specific and Applied Accounting, 3(3), 335-352.

Bressan, V. G. F., Braga, M. J., Bressan, A. A., \& Resende Filho, M. de A. (20II). Avaliação de insolvência em cooperativas de crédito: uma aplicação do Sistema Pearls. Revista de Administração Mackenzie, 12(2), II3-I44.

Bressan, V. G. F., Braga, M. J., \& Lima, J. E. de. (2004). Análise de insolvência das cooperativas de crédito rural do estado de Minas Gerais. Estudos Econômicos, 34(3), 553-585.

Bressan, V. G. F., Lopes, A. L. M., \& Menezes, M. R. (2013). Análise de eficiência das cooperativas de crédito brasileiras utilizando informações contábeis. Congresso Integrado de Contabilidade, Juiz de Fora, MG, Brasil, I.

Ceretta, P. S., \& Niederauer, C. A. P. (200I). Rentabilidade e eficiência no setor bancário brasileiro. Revista de Administração Contemporânea, 5(3), 7-27.

Dambros, M. A., Lima, J. F. de, \& Figueiredo, A. M. (2009). Sistema cooperativo de crédito SICREDI: um estudo da eficiência das cooperativas do Paraná. Gestão \& Regionalidade, 25(74), 22-34.

Dias, B. M. M. (20II). Uma análise de eficiência do sector bancário português. Dissertação de mestrado, Universidade do Minho, Braga, Portugal.

Fernandes, R. C. (1997). O que é o terceiro setor ? Revista do Legislativo, 18, 26-30.

Ferreira, M., Gonçalves, R., \& Braga, M. (2007). Investigação do desempenho das cooperativas de crédito de Minas Gerais por meio da Análise Envoltória de Dados (DEA). Economia Aplicada, 11(3), 425-445. Recuperado em 25 outubro, 20I3, de http://www.scielo.br/scielo.php?pid=Si4I3$80502007000300006 \&$ script=sci_arttext\&tlng=.

Freitas, M. C. P. de. (2009). Os efeitos da crise global no Brasil: aversão ao risco e preferência pela liquidez no mercado de crédito. Estudos Avançados, 23(66), I25-I45.

Fried, H. O., Lovell, C. K., \& Eeckaut, P. V. (I993). Evaluating the performance of US credit unions. Journal of Banking \& Finance, 17(92), 251-265.

Geriz, S. D. (2004). As cooperativas de crédito no arcabouço institucional do sistema financeiro nacional. Prima Facie-Direito, História e Política, (4), 82-IIo.

Goddard, J., McKillop, D., \& Wilson, J. (2002). The growth of US credit unions. Journal of Banking \& Finance, 26(I2), 2327-2356.

Hafemann, M., \& Floriano, J. (20I2). Participação em operações financeiras da cooperativa de crédito Sicoob Credisc de Joinville em relação à Sicoob Credisc em todo o estado de Santa Catarina 2007 a 20I0. VI Encontro de Economia Catarinense, Joiville, SC, Brasil, 6.

Hendriksen, E. S., \& Breda, M. F. van (20II). Teoria da Contabilidade (5a ed., p. 550). São Paulo: Atlas. International Co-Operative Alliance. (2013). What's a Co-op? Co-operative identity, values \& principles. Recuperado em Io setembro, 2013, de http://ica.coop/en/what-co-op/co-operative-identityvalues-principles 
Jacob, C. A. (2003). Crédito bancário no Brasil: uma interpretação heterodoxa. Tese de doutorado, Universidade Estadual de Campinas, São Paulo, SP, Brasil.

Kazmier, L. J. (2007). Estatística aplicada à administração e economia (4a ed., p. 386). Porto Alegre: Bookman.

Lei n. 5.764, de I6 de dezembro de I97I (1971). Define a Política Nacional de Cooperativismo, institui o regime jurídico das sociedades cooperativas, e dá outras providências. Diário Oficial da União. Brasília, DF: Poder Executivo.

Matarazzo, D. C. (2003). Análise financeira de balanços (6a ed., p. 457). São Paulo: Atlas.

Matias, A. B. (I999). Insucesso de grandes bancos privados brasileiros de varejo. Tese de livre-docência, Universidade de São Paulo, São Paulo, SP, Brasil.

Matias, A. B. (2009). Análise financeira fundamentalista de empresas (p. 384). São Paulo: Atlas.

Mélian, A., \& Cabo, P. (2006). El cooperativismo de crédito en el mundo. Una especial referencia a los paises de América Latina. VIII Reunión de Economía Mundial (pp. I-2I). Alicante, Espanha.

Melo Sobrinho, A. D. de, Soares, M. M., \& Meinen, Ê. (2013). A evolução do sistema cooperativista de crédito brasileiro em 20I2. Brasília: Sicoob.

Organização das Cooperativas Brasileiras. (2013). Cooperativismo: institucional. Recuperado em I8 setembro, 20I3, de http://www.ocb.org.br/site/cooperativismo/institucional.asp.

Pinheiro, M. A. H. (2008). Cooperativas de crédito: história da evolução normativa no Brasil (6a ed., p. 94). Brasília: BCB.

Portal Action. (2013). Teste binomial exata. Recuperado em 29 janeiro, 20I4, de http://www.portalaction.com.br/content/36-teste-binomial-exata

Quiroga, M. del P. S., Bressan, V. G. F., \& Braga, M. J. (2005). Avaliação financeira das cooperativas de crédito mútuo do estado de Minas Gerais. Revista de Ciências Empresariais da Unipar, 6(I), I-I9. Santos, C. A. dos. (2009). Cooperativa de crédito - Série empreendimentos coletivos (p. 45). Brasília: Sebrae.

Smith, D. J. (1986). A test for variant objective functions in credit unions. Applied Economics, 18(9), 959-970.

Smith, D. J., Cargill, T. F., \& Meyer, R. A. (I98I). An economic theory of a credit union. Journal of Finance, 36(2), 519-528.

Stefanello, E., Freitas, C. A. de, \& Staduto, J. A. R. (2004). Avaliação do desempenho financeiro dos bancos cooperativos no Brasil, Anais do Congresso de Economia e Sociologia Rural, Cuiabá, MT, Brasil, 42, I-I9.

Wheelock, D. C., \& Wilson, P. W. (2013). The evolution of cost-productivity and efficiency among US credit unions. Journal of Banking \& Finance, 37(I), 75-88. doi:Io.IoI6/j.jbankfin.2012.08.003.

World Council of Credit Unions. (20II). Statistical Report (pp. I-4).

World Council of Credit Unions. (2012). Statistical Report (pp. I-4). 